can increase his knowledge and understanding, and still remain humble and ennobled before the wonder and the majesty of what he does not understand.

As Dr. Caryl Haskins, president of the Carnegie Institution of Washington, recently remarked, it seems that the United States and Great Britain have problems in common with regard to the training of scientists and engineers and to the supply of the man-power of the right calibre. Dr. Killian's opinions as expressed in his address at the American Association proves this. All men of science and those concerned with scientific man-power problems would do well to read this address with the object of producing not only more, but also better educated, scientists and engineers in the future.

\section{PRINCIPLES OF THE DYNAMO}

Electromagnetic Principles of the Dynamo

By Prof. E. B. Moullin. (Oxford Engineering Science Series.) Pp. xi +367 . (Oxford: Clarendon Press ; London : Oxford University Press, 1955.) 50s, net.

T happens not altogether infrequently that a book I which has been projected and upon which a sub. stantial amount of work may have been done fails for one reason or another to achieve completion and publication. Most of those who, twenty-three years ago, read in the preface to Prof. E. B. Moullin's book, "Principles of Electromagnetism", that he hoped to publish shortly a book entitled the "Principles of the Direct Current Dynamo", must long ago have assumed that the volume would never now appear. On the contrary, this book, under the slightly altered title of the "Electromagnetic Principles of the Dynamo", has now taken its place in the literature of electrical machines.

Prof. Moullin explains in the preface that the manuscript, almost complete, lay aside from 1933 until 1950 and was then on the point of being discarded. At that time, Mr. G. E. Middleton, who had for many years been engaged on the design of electrical machines, joined the staff of the University of Cambridge, and he was invited to read the manuscript and express an opinion as to whether it would still be worth while to complete the book. Happily, Mr. Middleton recommended the completion of the task, and the author records his appreciation of the invaluable help rendered by him in the completion and revision of the manuscript.

The book conforms closely to the terms of its title and deals almost exclusively with the electromagnetic principles of direct-current machines. After an initial chapter on basic principles come five chapters dealing individually with the estimation of the ampere turns on the poles, the magnetic effects of the armature current, characteristic curves, efficiency and energy losses and commutation. These are followed by two chapters, one of which deals with a group of special machines, and the other, the last chapter, is entitled "Supplementary Matter". This treats in considerable detail certain topics which have been dealt with less fully earlier in the book and with a number of problems which link alternatingcurrent with direct-current machines.

Perhaps the essential quality of this book can best be described by saying that, in it, the author has asked himself and has answered to his own satis- faction most of the searching and often awkward questions which an acute and critical mind would ask when presented with the conventional treatments of the theory of electromagnetic machines. Many of the paradoxes and conundrums which tantalized electrical engineers of an earlier generation receive serious study and elucidation. The induction of the electromotive force in the homopolar machine, the magnetic force on conductors embedded in slots and the e.m.f. in such conductors are examples of these problems. The treatments which are given of such topics as commutation and of the load characteristics of machines are exceptionally thorough and penetrating. There is a particularly interesting analysis of the Rosenberg dynamo, a machine which has nowadays a greatly increased interest as it is, in principle, the prototype of an important class of control machine.

At the end of the book is a collection of examples, eighty in number, taken for the most part from Cambridge examination papers, which illustrate the topics discussed in the text, each example being accompanied by an outline of its solution.

Mathematical analysis is used in varying degree in relation to nearly all the subjects with which the book deals, but no advanced methods are involved. The standard required is well within the competence of a second-or third-year university student. The real interest lies, however, in the critical questioning of the assumptions underlying many accepted pieces of theory and in their justification often by more than one method. This searching examination of the physics of machine problems, with the consequent quantitative assessment of the validity of assumptions, not only illuminates the problems themselves but also illustrates that spirit of inquiry which is an essential characteristic of the scientific mind.

This is a stimulating book which will interest and satisfy the teacher concerned with the subject of electromagnetic machines, and it will do the like for the student whose intellectual curiosity and insight have crossed the 'pons asinorum' of his subject. While it is clearly for the student that this book has been written, it is not too much to say that the experienced designer of electrical machines may find in its pages a new approach to some fundamental matter which may elucidate an intractable practical problem.

J. Greig

\section{OPTICS OF CHARGED PARTICLES}

Handbuch der Physik

Herausgegeben von S. Flügge. Band 33: Korpuskularoptik. Pp. vi+702. (Berlin: Springer-Verlag, 1956.) 122.50 D. marks.

HE first volumes of the new "Handbuch der Physik" are out and give every promise of its being a worthy successor to the original edition of Geiger and Scheel, which appeared between 1926 and 1930. The intervening quarter of a century has seen some notable advances in international co-operation as well as great progress in physics itself, and both developments are reflected in the new edition. The contributors are drawn from many countries, and the articles may be in English, French or German. The progress of physics is reflected in the complete recasting of the treatment and its extension to fifty-four volumes. The change is exemplified in the subject-matter of Vol. 33, "Korpuskularoptik", one of the first of the new series to appear. Vol. 22 of 